\title{
Treadmill training after spinal cord injury: It's not just about the walking
}

\author{
Audrey L. Hicks, PhD; ${ }^{*}$ Kathleen A. Martin Ginis, PhD \\ Department of Kinesiology, McMaster University, Hamilton, ON, Canada
}

\begin{abstract}
Body weight-supported treadmill training (BWSTT) is being used throughout the world as a method for improving functional ambulation after spinal cord injury (SCI). This therapy, however, is very labor-intensive, and recent evidence suggests that it may not be superior to other more conventional forms of rehabilitation for improving locomotor ability. Recognizing that the value of BWSTT may extend well beyond its potential to improve functional ambulation is important, and the physiological and psychological benefits associated with this whole-body upright exercise may justify its use in both the acute and chronic SCI populations.
\end{abstract}

Key words: body weight-supported treadmill training, cardiovascular disease, exercise, health benefits, health risks, muscle composition, psychological benefit, rehabilitation, spinal cord injury, walking.

\section{INTRODUCTION}

Over the past decade, body weight-supported treadmill training (BWSTT) has emerged as a promising method for improving functional ambulation after spinal cord injury (SCI). Early reports of this therapy were very promising [1-4], yet a recent multicenter randomized clinical trial suggested that even though BWSTT may improve locomotor ability in the acute SCI population, it may not be superior to more conventional forms of rehabilitation in which the same amount of time is devoted to walking [5]. What most of these studies have neglected to address, however, is the efficacy of BWSTT as an exercise intervention for the SCI population.
The SCI population is considered one of the most inactive of all segments of society. This inactivity is a serious health issue given that it can lead to a variety of secondary health complications and a decline in physical capacity over and above that caused by the SCI [6]. People who are wheelchair-dependent invariably rely on upper-body exercise as a means to optimal fitness. While good evidence exists that various upper-body exercises can improve both strength and cardiovascular endurance [7-9], exercise of a larger muscle mass (i.e., the legs) is a greater physiological challenge and likely results in greater increases in fitness, cardiovascular function, and metabolic control. We also cannot disregard the potential psychological benefits associated with upright walking exercise in wheelchair-dependent individuals. Therefore, before BWSTT is dismissed as an expensive, but perhaps not superior, alternative to conventional rehabilitation after SCI, we need to consider the potential effect of this therapy on a variety of health-related outcomes.

\footnotetext{
Abbreviations: ASIA = American Spinal Injury Association, $\mathrm{BMD}=$ bone mineral density, BWSTT = body weight-supported treadmill training, CVD = cardiovascular disease, FES = functional electrical stimulation, HDL = high-density lipoprotein, HRQOL = health-related quality of life, LDL = low-density lipoprotein, $\mathrm{PWB}=$ psychological well-being, $\mathrm{SCI}$ = spinal cord injury.

*Address all correspondence to Audrey L. Hicks, PhD; Department of Kinesiology, McMaster University, 1280 Main St West, Hamilton, ON L8S 4K1, Canada; 905-525-9140, ext 24643; fax: 905-525-7629. Email: hicksal@mcmaster.ca DOI: 10.1682/JRRD.2007.02.0022
} 
Advances in acute medical management following SCI have greatly improved survival rates. Given that the majority of SCIs occur in young adulthood, people with SCI live many years with their disability and the associated morbidity. Although life expectancy for people with SCI has steadily increased over the last few decades, it is still somewhat lower than for the nondisabled population [10-11]. Recently, investigators have reported that much of the excess (and early) morbidity and mortality in people with chronic SCI relates to potentially treatable factors, such as cardiovascular disease (CVD), diabetes, and smoking-related illnesses [12]. This fact certainly highlights the importance of promoting interventions that can improve health, fitness, and overall quality of life in this population. In this article, we will discuss BWSTT as one such intervention that we believe shows tremendous promise for improving both physical and psychological health in people with SCI.

\section{SECONDARY HEALTH COMPLICATIONS AFTER SCI AND ROLE OF BWSTT}

\section{Changes in Cardiovascular Fitness and Function After SCI}

CVD is the leading cause of death in both the nondisabled and SCI populations [13-14], but evidence suggests that people with SCI may have an earlier onset and an increased prevalence of CVD compared with the general population [15-16]. Physical inactivity may be one of the key mechanisms behind this increased risk since it is recognized both as a major independent risk factor for CVD and an important modifier for a number of other risk factors for this disease.

For example, elevated serum lipid concentrations, specifically triglycerides, total cholesterol, and low-density lipoprotein (LDL) cholesterol are associated with the development of atherosclerotic plaques and progression of CVD. Cross-sectional investigations have shown that people with SCI have elevated LDL cholesterol, total cholesterol, and triglycerides and reduced high-density lipoprotein (HDL) cholesterol compared with nondisabled controls [17-19], all of which increase the risk of CVD.

Another factor contributing to atherogenesis is persistent hyperglycemia, a condition resulting from progressive insulin resistance and associated with type 2 diabetes [20-21]. Reduced glucose tolerance (due to increased insulin resistance) and abnormal glucose homeostasis are also commonly observed in people with chronic SCI
[19,22-23], and both increase the risks for type 2 diabetes and CVD in this population.

Finally, cardiovascular function very much depends on a healthy vascular endothelium, in which the arteries readily expand and recoil with changes in pressure. This vascular characteristic is controlled by the autonomic nervous system and, therefore, can be significantly affected by SCI [24]. An increase in arterial stiffness (i.e., reduced compliance) has been indicated as the number one factor associated with CVD progression [25], and increased femoral artery stiffness and associated endothelial dysfunction have been observed in the SCI population [26-27].

Based on these observations, we are not surprised that the SCI population appears to be significantly more vulnerable to CVD than the nondisabled population, but another troubling statistic is that people with SCI tend to develop CVD at younger ages [12-13,28]. Since physical inactivity and low fitness are also recognized as primary risk factors for CVD [29], initiatives that focus on increasing exercise could have important implications for decreasing CVD incidence and progression (through modification of other risk factors) in the SCI population.

\section{Effects of BWSTT on Cardiovascular Fitness and Function}

To date, no published reports demonstrate the efficacy of BWSTT in reducing CVD in the SCI population, but we have promising evidence that several of the risk factors for CVD can be significantly reduced with regular BWSTT. We have been able to demonstrate that 6 months of regular BWSTT (three times a week) improves the blood lipid profile of people with incomplete SCI (American Spinal Injury Association [ASIA] classification C) by decreasing LDL cholesterol and the ratio between total cholesterol and HDL cholesterol [30]. Similarly, this same training load improved glucose tolerance and insulin sensitivity in participants with SCI [31].

We also have evidence that BWSTT improves both the autonomic regulation of heart rate and blood pressure and causes positive changes in vascular dynamics in the femoral and carotid arteries [32-34] in people with motorcomplete (ASIA B) and motor-incomplete (ASIA C) SCI, all of which may have important implications with respect to CVD risk. We hypothesize that BWSTT, through its involvement of a larger muscle mass and the postural challenge of being upright, may provide a greater stimulus for inducing positive cardiovascular changes than more traditional exercise protocols such as arm exercise and functional electrical stimulation (FES). 


\section{CHANGES IN BODY COMPOSITION AFTER SCI}

\section{Muscle Composition-Metabolism}

The first 6 to 12 months after traumatic SCI are characterized by severe muscle atrophy and changes in the distribution of muscle fiber types. Significant atrophy of type I, IIa, and IIx fibers (up to 68 percent) has been reported within the first 6 months postinjury, together with a conversion among type II fiber subtypes [35-36]. The typical fiber type transformation that occurs soon after SCI is an increased proportion of the highly fatigable type IIx fiber, with a corresponding reduction in the type IIa and possibly type I fiber types [35-36]. The observed changes in muscle fiber type distribution during the first year after SCI are presumably accompanied by changes in the regulation of muscle energy metabolism; however, relatively little work has been conducted to confirm this hypothesis. The available evidence from both human [35] and animal [37] studies suggests that SCI leads to a marked decrease in mitochondrial oxidative metabolism and an increase in nonoxidative energy provision.

One of the negative consequences of a significantly reduced skeletal muscle mass is a reduction in glucose tolerance and a corresponding increase in risk of developing type 2 diabetes. The incidence of reduced glucose tolerance among persons with SCI has been shown to be significantly higher than in the nondisabled population $[16,38]$, likely resulting from both reduced skeletal muscle mass [16] and reduced neural input to paralyzed muscles [22,29].

\section{Effects of BWSTT on Muscle Composition-Metabolism}

Activity-based interventions show tremendous promise for improving muscle mass after SCI. We have shown that after 6 months of BWSTT (three times a week) in people with chronic SCI (average 7 years postinjury), mean fiber area increased 25 percent, percentage area occupied by type IIax/IIx fibers decreased, and percentage area occupied by type IIa fibers increased [30]. These changes were accompanied by a 39 percent increase in citrate synthase activity, providing evidence for improved oxidative capacity. We also have evidence that by implementing BWSTT in the first 6 months postinjury at a frequency of only two times a week, the predicted muscle atrophy and fiber type redistribution can be prevented [39-40]. We should note that the majority of participants in the latter study were classified as motor-complete (ASIA B). Thus, BWSTT is effective in both the prevention and treatment of SCI-induced muscle atrophy.
An improvement in muscle mass and muscle composition is important not only for improving strength and function for potential reattainment of ambulation but also for other significant health benefits associated with an increase in muscle mass, specifically glucose tolerance and type 2 diabetes risk (see previous section). BWSTT has been shown to improve glucose tolerance, glucose transporter content, and insulin sensitivity in people with chronic SCI [31]. Participants in Phillips et al.'s study underwent a modified oral glucose tolerance test before and after 6 months of BWSTT. Following training, a significant decrease in both the insulin and glucose response to a standard glucose load was present, along with a more than two-fold increase in the content of GLUT-4 (glucose transport protein, isoenzyme 4) [31]. These results are in agreement with previously published reports of the effects of FES cycle ergometry on these same outcomes $[22,41-42]$.

\section{Fat Mass}

While skeletal muscle mass decreases post-SCI, fat mass (absolute and percentage of body weight) increases. Fat mass of persons with chronic SCI ranges from 23 to 35 percent of body weight [43-45], consistent with the definitions of overweight and obese [46]. Obesity, specifically visceral abdominal fat, is strongly and independently associated with numerous CVD risk factors in nondisabled persons, including dyslipidemia, hyperinsulinemia, glucose intolerance, and hypertension [47]. Despite the prevalence of many of these same risk factors in the SCI population, few studies have determined the relationship between measured fat mass (and none between visceral abdominal fat) and CVD risk factors in persons with SCI.

\section{Effects of Exercise on Fat Mass}

The ability of exercise to decrease total fat mass and attenuate fat mass accretion in nondisabled adults is widely recognized [48]. Even in the absence of weight loss, exercise reduces visceral abdominal fat and insulin resistance [49]. Few prospective studies in the SCI literature have measured the relationship between exercise and body fat, but a recent article from Japan suggests that exercise is associated with reduced percentage body fat, waist circumference, and waist:hip ratio in athletes with SCI [50]. To date, BWSTT has not been shown to reduce total fat mass in people with SCI; based on whole-body dual-energy X-ray absorptiometry scans, fat mass remained unchanged after 12 months of BWSTT in the chronic SCI 
population [31] and slightly elevated after 6 months of BWSTT in those with acute SCI [41]. Exercise regimes need to be fairly intense and of sufficient frequency to result in a decrease in total fat mass, and a BWSTT frequency of two to three times a week likely does not result in enough energy expenditure for the energy balance equation to change. However, future studies should focus on the effects of BWSTT on visceral fat stores since the exercise stimulus associated with BWSTT may improve fat distribution in the SCI population, even in the absence of changes in total fat mass.

\section{Bone Mass}

Bone loss after SCI is rapid, likely beginning within 2-4 days of injury [51]. The highest rate of bone mineral loss occurs in the first 1-2 years postinjury, is most evident in appendicular areas below the level of the lesion (i.e., leg bones), and is more prominent in trabecular versus cortical bone [52]. The decrease in mechanical loading together with neural, vascular, and hormonal changes associated with the injury all contribute to the substantial loss in bone mineral density (BMD). The skeletal fragility resulting from this progressive loss in BMD is associated with an increased incidence of osteoporosis and lower-limb fractures in the SCI population [52]. Age and time since injury are positively correlated with fracture risk, and as in the nondisabled population, women are more prone to fragility fractures than men [53].

\section{Effects of BWSTT on Bone Mass}

Although the study numbers are low, no evidence exists that activity-based therapies can prevent the bone loss associated with SCI. In the only BWSTT study that investigated BMD in the acute SCI population, the twice weekly training frequency could not prevent losses in BMD in the study participants [40], although no nonexercising control group was included for comparison. Researchers have also studied whether activity-based interventions can attenuate the rate of loss or possibly improve BMD in the chronic SCI population. In contrast to the several studies that have shown FES to improve BMD [54-57], BWSTT has not been shown to increase BMD in people with chronic SCI [58]. Differences in training frequency and/or duration likely account for the apparent superiority of FES; frequencies of two to three times a week of BWSTT or FES do not appear to be a sufficient stimulus for bone formation [54,57], yet five times a week may be more effective [55-56].

\section{CHANGES IN PSYCHOLOGICAL WELL-BEING AND HEALTH-RELATED QUALITY OF LIFE AFTER SCI}

SCI is typically accompanied by a loss of independence, increased family and caregiver load, and reduced vocational and social participation by the injured person. These consequences can have a profound impact on psychological well-being (PWB) and health-related quality of life (HRQOL) [59-61] and are further exacerbated by physical inactivity [62]. Inactivity can compromise the ability to live independently and maintain a sense of personal autonomy and control over one's life. Indeed, some investigators estimate that as a result of inactivity-related decrements, only 25 percent of healthy young persons with paraplegia, and even fewer with tetraplegia, have the minimum level of fitness needed to perform the activities of daily living necessary to maintain independent living [62-63]. Similarly, only 26 to 32 percent of Canadians with SCI are employed and able to fulfill social roles such as "provider" or "caregiver" [11]. The majority are unable to return to work because they can no longer fulfill the physical demands of their jobs. Although partly attributable to the SCI itself, a reduction in work capacity is also a function of physical inactivity [63]. Of additional concern, depression and anxiety are far more prevalent in the SCI population than the general population [64-65], and people with SCI who are inactive are more likely to experience these psychopathologies than their active counterparts [66-67].

\section{EFFECTS OF BWSTT ON PSYCHOLOGICAL WELL-BEING AND HEALTH-RELATED QUALITY OF LIFE}

The few studies that have examined the effects of BWSTT on HRQOL and PWB have produced encouraging results. With regard to changes in HRQOL, two studies have shown that BWSTT is associated with improvements in overall life satisfaction [68-69] and in specific dimensions of HRQOL, including satisfaction with health and functioning and social and economic well-being [69]. These studies also showed improvements in aspects of PWB. Specifically, BWSTT was associated with improvements in overall PWB [69] and body image [68-69].

In contrast, the limited research to date has not shown any effects of BWSTT on depression [69-70]. These null effects must be interpreted with caution, however, given 
the relatively small study sample sizes and the very low levels of depressive symptoms reported by participants at study baseline. Given that single acute bouts of BWSTT have small- to medium-sized positive effects on mood [71], the cumulative effects of multiple bouts of BWSTT could improve PWB among people with higher levels of depressive symptomatology.

How might BWSTT improve HRQOL and PWB? Certainly any intervention that improves functioning and independence can have concomitant effects on these endpoints. For example, if BWSTT improves participants' ability to stand or transfer into a car, it can profoundly affect independence which, in turn, can influence how people feel about themselves and their quality of life [69]. Another possibility is that like other forms of exercise training [72], BWSTT improves PWB and HRQOL vis-á-vis reductions in pain. Indeed, the mood improvements observed in Martin Ginis and Latimer's study of BWSTT were significantly correlated with decreases in pain [71]. In addition, BWSTT may improve one's sense of self; for individuals who are wheelchair-reliant, BWSTT provides an opportunity to stand upright, look people directly in the eye, and engage in the "normative and desirable" activity of walking [69]. Many BWSTT participants also report a positive emotional thrill associated with engaging in "the inspirational activity of seeing themselves walk again” [69, p. 101]. Taken together, these reports suggest that even if people do not regain their ability to walk after training, BWSTT is a potentially powerful stimulus for improving aspects of their HRQOL and PWB.

\section{CONCLUSIONS AND FUTURE DIRECTIONS}

While BWSTT has received most of its research attention on the basis of its potential to improve functional ambulation in people with SCI, we must also recognize the value of this intervention as a whole-body exercise therapy. Not only do wheelchair-dependent individuals enjoy and value the normalizing experience of seeing themselves upright and participating in the walking motion, regular exposure to BWSTT results in some very significant health-related benefits that may decrease the risk of secondary health complications. Given that people with SCI are (1) living longer and (2) at increased and earlier risk for secondary health complications associated with physical inactivity, the importance of providing opportunities for full-body exercise cannot be overemphasized. The labor/ equipment costs associated with BWSTT are significant, however, and further studies are needed to provide definitive evidence of the cost:benefit ratio. In this regard, the potential efficacy of robotic devices to assist with locomotor training should also be explored, since these devices may be less costly in the long run than traditional manual training.

In summary, compelling evidence exists that BWSTT has the potential to produce important physical and psychological improvements in people with SCI. Furthermore, these training-induced adaptations do not appear to be dependent on the degree of functional walking improvement; in fact, they even occur in individuals who would not normally be expected to improve their locomotor ability (e.g., ASIA B). Clearly, important healthrelated gains are being achieved through BWSTT, and future research should now focus on potential long-term health benefits. The important next step for community translation will be to establish a clear link between participation in locomotor training and reduced morbidity from secondary health complications in the SCI population. This evidence will be crucial in informing the scope and nature of the rehabilitation process after SCI.

\section{ACKNOWLEDGMENTS}

This material is the result of work supported by a Canadian Institute of Health New Investigator Award to K. Martin Ginis.

The authors have declared that no competing interests exist.

\section{REFERENCES}

1. Visintin M, Barbeau $\mathrm{H}$. The effects of parallel bars, body weight support and speed on the modulation of the locomotor pattern of spastic paretic gait. A preliminary communication. Paraplegia. 1994;32(8):540-53. [PMID: 7970859]

2. Wernig A, Müller S, Nanassy A, Cagol E. Laufband therapy based on "rules of spinal locomotion" is effective in spinal cord injured persons. Eur J Neurosci. 1995;7(4):823-29.

[PMID: 7620630]. Erratum in Eur J Neurosci. 1995;7(6): 1429.

3. Wernig A, Nanassy A, Müller S. Maintenance of locomotor abilities following Laufband (treadmill) therapy in paraand tetraplegic persons: Follow-up studies. Spinal Cord. 1998;36(11):744-49. [PMID: 9848480] 
4. Wirz M, Colombo G, Dietz V. Long term effects of locomotor training in spinal humans. J Neurol Neurosurg Psychiatry. 2001;71(1):93-96. [PMID: 11413270]

5. Dobkin B, Apple D, Barbeau H, Basso M, Behrman A, Deforge D, Ditunno J, Dudley G, Elashoff R, Fugate L, Harkema S, Saulino M, Scott M; Spinal Cord Injury Locomotor Trial Group. Weight-supported treadmill vs over-ground training for walking after acute incomplete SCI. Neurology. 2006;66(4):484-93. [PMID: 16505299]

6. Martin Ginis KA, Hicks AL. Exercise research issues in the spinal cord injured population. Exerc Sport Sci Rev. 2005; 33(1):49-53. [PMID: 15640721]

7. Davis G, Plyley MJ, Shephard RJ. Gains of cardiorespiratory fitness with arm-crank training in spinally disabled men. Can J Sport Sci. 1991;16(1):64-72. [PMID: 1645221$]$

8. Hicks AL, Martin KA, Ditor DS, Latimer AE, Craven C, Bugaresti J, McCartney N. Long-term exercise training in persons with spinal cord injury: Effects on strength, arm ergometry performance and psychological well-being. Spinal Cord. 2003;41(1):34-43. [PMID: 12494319]

9. Hooker SP, Wells CL. Effects of low- and moderate-intensity training in spinal cord-injured persons. Med Sci Sports Exerc. 1989;21(1):18-22. [PMID: 2494416]

10. Yeo JD, Walsh J, Rutkowski S, Soden R, Craven M, Middleton J. Mortality following spinal cord injury. Spinal Cord. 1998;36(5):329-36. [PMID: 9601112]

11. Rick Hansen Spinal Cord Injury Registry (RHSCIR) [homepage on the Internet]. Vancouver (Canada): RHSCIR; c200507 [cited 2006 Dec]. Spinal cord injury facts and statistics; [1 screen]. Available from: http://rickhansenregistry.org/ page192.htm

12. Garshick E, Kelley A, Cohen SA, Garrison A, Tun CG, Gagnon D, Brown R. A prospective assessment of mortality in chronic spinal cord injury. Spinal Cord. 2005;43(7): 408-16. [PMID: 15711609]

13. Bauman WA, Spungen AM, Raza M, Rothstein J, Zhang RL, Zhong YG, Tsuruta M, Shahidi R, Pierson RN Jr, Wang J, et al. Coronary artery disease: Metabolic risk factors and latent disease in individuals with paraplegia. $\mathrm{Mt}$ Sinai J Med. 1992;59(2):163-68. [PMID: 1574072]

14. Whiteneck GG, Charlifue SW, Frankel HL, Fraser MH, Gardner BP, Gerhart KA, Krishnan KR, Menter RR, Nuseibeh I, Short DF, Siver JR. Mortality, morbidity, and psychosocial outcomes of persons with spinal cord injury more than 20 years ago. Paraplegia. 1992;30(9):617-30. [PMID: 1408338]

15. Yekutiel M, Brooks ME, Ohry A, Yarom J, Carel R. The prevalence of hypertension, ischaemic heart disease and diabetes in traumatic spinal cord injured patients and amputees. Paraplegia. 1989;27(1):58-62. [PMID: 2784200]

16. Bauman WA, Kahn NN, Grimm DR, Spungen AM. Risk factors for atherogenesis and cardiovascular autonomic func- tion in persons with spinal cord injury. Spinal Cord. 1999; 37(9):601-16. [PMID: 10490851]

17. Brenes G, Dearwater S, Shapera R, LaPorte RE, Collins E. High density lipoprotein cholesterol concentrations in physically active and sedentary spinal cord injured patients. Arch Phys Med Rehabil. 1986;67(7):445-50. [PMID: 3729689]

18. Schmid A, Halle M, Stützle C, König D, Baumstark MW, Storch MJ, Schmidt-Trucksäss A, Lehmann M, Berg A, Keul J. Lipoproteins and free plasma catecholamines in spinal cord injured men with different injury levels. Clin Physiol. 2000;20(4):304-10. [PMID: 10886263]

19. Bauman WA, Adkins RH, Spungen AM, Kemp BJ, Waters RL. The effect of residual neurological deficit on serum lipoproteins in individuals with chronic spinal cord injury. Spinal Cord. 1998;36(1):13-17. [PMID: 9471131]

20. Goldberg RB. Prevention of type 2 diabetes. Med Clin North Am. 1998;82(4):805-21. [PMID: 9706122]

21. Huang ES, Meigs JB, Singer DE. The effect of interventions to prevent cardiovascular disease in patients with type 2 diabetes mellitus. Am J Med. 2001;111(8):633-42. [PMID: 11755507]

22. Chilibeck PD, Bell G, Jeon J, Weiss CB, Murdoch G, MacLean I, Ryan E, Burnham R. Functional electrical stimulation exercise increases GLUT-1 and GLUT-4 in paralyzed skeletal muscle. Metabolism. 1999;48(11):1409-13. [PMID: 10582549]

23. Manns PJ, McCubbin JA, Williams DP. Fitness, inflammation, and the metabolic syndrome in men with paraplegia. Arch Phys Med Rehabil. 2005;86(6):1176-81. [PMID: 15954057]

24. Wecht JM, Weir JP, DeMeersman RE, Spungen AM, Bauman WA. Arterial stiffness in persons with paraplegia. J Spinal Cord Med. 2004;27(3):255-59. [PMID: 15478529]

25. Arnett DK, Evans GW, Riley WA. Arterial stiffness: A new cardiovascular risk factor? Am J Epidemiol. 1994;140(8): 669-82. [PMID: 7942769]

26. De Groot PC, Van Kuppevelt DH, Pons C, Snoek G, Van der Woede LH, Hopman MT. Time course of arterial vascular adaptations to inactivity and paralyses in humans. Med Sci Sports Exerc. 2003;35(12):1977-85. [PMID: 14652491]

27. Hopman MT, Groothuis JT, Flendrie M, Gerrits KH, Houtman S. Increased vascular resistance in paralyzed legs after spinal cord injury is reversible by training. J Appl Physiol. 2002;93(6):1966-72. [PMID: 12433934]

28. Bauman WA, Raza M, Spungen AM, Machac J. Cardiac stress testing with thallium-201 imaging reveals silent ischemia in individuals with paraplegia. Arch Phys Med Rehabil. 1994;75(9):946-50. [PMID: 8085927]

29. Myers J, Prakash M, Froelicher V, Do D, Partington S, Atwood JE. Exercise capacity and mortality among men referred for exercise testing. N Engl J Med. 2002;346(11): 793-801. [PMID: 11893790] 
30. Stewart BG, Tarnopolsky MA, Hicks AL, McCartney N, Mahoney DJ, Staron RS, Phillips SM. Treadmill traininginduced adaptations in muscle phenotype in persons with incomplete spinal cord injury. Muscle Nerve. 2004;30(1): 61-68. [PMID: 15221880]

31. Phillips SM, Stewart BG, Mahoney DJ, Hicks AL, McCartney N, Tang JE, Wilkenson SB, Armstrong D, Tarnopolsky MA. Body-weight-support treadmill training improves blood glucose regulation in persons with incomplete spinal cord injury. J Appl Physiol. 2004;97(2):716-24. [PMID: 15107410$]$

32. Crozier J, Ditor DS, Adams MM, Smith R, Campbell A, Hicks AL, MacDonald MJ. The effects of BWSTT on cardiovascular structure and function and functional walking ability in sub-acute spinal cord injury. Physiologist. 2004;47: 323-24.

33. Ditor DS, MacDonald MJ, Kamath MV, Bugaresti J, Adams M, McCartney N, Hicks AL. The effects of bodyweight supported treadmill training on cardiovascular regulation in individuals with motor-complete SCI. Spinal Cord. 2005;43(11):664-73. [PMID: 15968298]

34. Ditor DS, Kamath MV, MacDonald MJ, Bugaresti J, McCartney N, Hicks AL. Effects of body-weight supported treadmill training on heart rate variability and blood pressure variability in individuals with spinal cord injury. J Appl Physiol. 2005;98(4):1519-25. [PMID: 15563629]

35. Castro MJ, Apple DF Jr, Staron RS, Campos GE, Dudley GA. Influence of complete spinal cord injury on skeletal muscle within 6 mo of injury. J Appl Physiol. 1999;86(1): 350-58. [PMID: 9887150]

36. Crameri RM, Weston AR, Rutkowski S, Middleton JW, Davis GM, Sutton JR. Effects of electrical stimulation leg training during the acute phase of spinal cord injury: A pilot study. Eur J Appl Physiol. 2000;83(4-5):409-15. [PMID: 11138583]

37. Durozard D, Gabrielle C, Baverel G. Metabolism of rat skeletal muscle after spinal cord transection. Muscle Nerve. 2000;23(10):1561-68. [PMID: 11003792]

38. Karlsson AK. Insulin resistance and sympathetic function in high spinal cord injury. Spinal Cord. 1999;37(7):494-500. [PMID: 10438116]

39. Adams MM, Smith R, Parisi G, Tarnopolosky MA, Phillips SM, McCartney N, Hicks AL. Effects of early body-weight supported treadmill training on muscle morphology after spinal cord injury [abstract]. Can J Appl Physiol. 2004;29:S34.

40. Giangregorio LM, Hicks AL, Webber CE, Phillips SM, Craven BC, Bugaresti JM, McCartney N. Body weight supported treadmill training in acute spinal cord injury: Impact on muscle and bone. Spinal Cord. 2005;43(11): 649-57. [PMID: 15968302]

41. Hjeltnes N, Galuska D, Björnholm M, Aksnes AK, Lannem A, Zierath JR, Wallberg-Henriksson H. Exercise-induced overexpression of key regulatory proteins involved in glucose uptake and metabolism in tetraplegic persons: Molecular mechanism for improved glucose homeostasis. FASEB J. 1998;12(15):1701-12. [PMID: 9837860]

42. Jeon JY, Weiss CB, Steadward RD, Ryan E, Burnham RS, Bell G, Chilibeck P, Wheeler GD. Improved glucose tolerance and insulin sensitivity after electrical stimulationassisted cycling in people with spinal cord injury. Spinal Cord. 2002;40(3):110-17. [PMID: 11859437]

43. Buchholz AC, McGillivray CF, Pencharz CB. Physical activity levels are low in free-living adults with chronic paraplegia. Obes Res. 2003;11(4):563-70. [PMID: 12690086]

44. Kocina P. Body composition of spinal cord injured adults. Sports Med. 1997;23(1):48-60. [PMID: 9017859]

45. Spungen AM, Adkins RH, Stewart CA, Wang J, Pierson RN Jr, Waters RL, Bauman WA. Factors influencing body composition in persons with spinal cord injury: A crosssectional study. J Appl Physiol. 2003;95(6):2398-2407. [PMID: 12909613]

46. Bray GA. In defense of a body mass index of 25 as the cut-off point for defining overweight. Obes Res. 1998;6(6):461-62. [PMID: 9845237]

47. Després JP. Abdominal obesity as important component of insulin-resistance syndrome. Nutrition. 1993;9(5):452-59. [PMID: 8286886]

48. Kyle UG, Gremion G, Genton L, Slosman DO, Golay A, Pichard C. Physical activity and fat-free and fat mass by bioelectrical impedance in 3853 adults. Med Sci Sports Exerc. 2001;33(4):576-84. [PMID: 11283433]

49. Ross R, Freeman JA, Janssen I. Exercise alone is an effective strategy for reducing obesity and related comorbidities. Exerc Sport Sci Rev. 2000;28(4):165-70. [PMID: 11064850]

50. Inukai Y, Takahashi K, Wang DH, Kira S. Assessment of total and segmental body composition in spinal cordinjured athletes in Okayama prefecture of Japan. Acta Med Okayama. 2006;60(2):99-106. [PMID: 16680186]

51. Bauman WA, Spungen AM. Metabolic changes in persons after spinal cord injury. Phys Med Rehabil Clin N Am. 2000; 11(1):109-40. [PMID: 10680161]

52. Jiang SD, Dai LY, Jiang LS. Osteoporosis after spinal cord injury. Osteoporos Int. 2006;17(2):180-92. [PMID: 16217589]

53. Garland DE, Adkins RH, Stewart CA, Ashford R, Vigil D. Regional osteoporosis in women who have a complete spinal cord injury. J Bone Joint Surg Am. 2001;83-A(8): 1195-1200. [PMID: 11507128]

54. Bélanger M, Stein RB, Wheeler GD, Gordon T, Leduc B. Electrical stimulation: Can it increase muscle strength and reverse osteopenia in spinal cord injured individuals? Arch Phys Med Rehabil. 2000;81(8):1090-98. [PMID: 10943761]

55. Chen SC, Lai CH, Chan WP, Huang MH, Tsai HW, Chen JJ. Increases in bone mineral density after functional electrical 
stimulation cycling exercises in spinal cord injured patients. Disabil Rehabil. 2005;27(22):1337-41. [PMID: 16321917]

56. Leeds EM, Klose KJ, Ganz W, Serafini A, Green BA. Bone mineral density after bicycle ergometry training. Arch Phys Med Rehabil. 1990;71(3):207-9. [PMID: 2317139]

57. Mohr T, Podenphant J, Biering-Sorensen F, Galbo H, Thamsberg G, Kjaer M. Increased bone mineral density after prolonged electrically induced cycle training of paralyzed limbs in spinal cord injured man. Calcif Tissue Int. 1997;61(1):22-25. [PMID: 9192506]

58. Giangregorio LM, Webber CE, Phillips SM, Hicks AL, Craven BC, Bugaresti JM, McCartney N. Can body weight supported treadmill training increase bone mass and reverse muscle atrophy in individuals with chronic incomplete spinal cord injury? Appl Physiol Nutr Metab. 2006; 31(3):283-91. [PMID: 16770357]

59. Dijkers M. Quality of life after spinal cord injury: A metaanalysis of the effects of disablement components. Spinal Cord. 1997;35(12):829-40. [PMID: 9429262]

60. Kannisto M, Merikanto J, Alaranta H, Hokkanen H, Sintonen $\mathrm{H}$. Comparison of health-related quality of life in three subgroups of spinal cord injury patients. Spinal Cord. 1998;36(3):193-99. [PMID: 9554021]

61. Post MW, Van Dijk AJ, Van Asbeck FW, Schrijvers AJ. Life satisfaction of persons with spinal cord injury compared to a population group. Scand J Rehabil Med. 1998; 30(1):23-30. [PMID: 9526751]

62. Noreau L, Shephard RJ. Spinal cord injury, exercise and quality of life. Sports Med. 1995;20(4):226-250. [PMID: 8584848]

63. Noreau L, Shephard RJ, Simard C, Paré G, Pomerleau P. Relationship of impairment and functional ability to habitual activity and fitness following spinal cord injury. Int J Rehabil Res. 1993;16(4):265-75. [PMID: 8175229]

64. Fuhrer MJ, Rintala DH, Hart KA, Clearman R, Young ME. Depressive symptomatology in persons with spinal cord injury who reside in the community. Arch Phys Med Rehabil. 1993;74(3):255-60. [PMID: 8439251]
65. Kennedy P, Rogers BA. Anxiety and depression after a spinal cord injury: A longitudinal analysis. Arch Phys Med Rehabil. 2000;81(7):932-37. [PMID: 10896007]

66. Coyle CP, Shank JW, Kinney W, Hutchins DA. Psychosocial functioning and changes in leisure lifestyle among individuals with chronic secondary health problems related to spinal cord injury. Ther Recreation J. 1993;27(4):239-52.

67. Muraki S, Tsunawake N, Hiramatsu S, Yamasaki M. The effect of frequency and mode of sports activity on the psychological status in tetraplegics and paraplegics. Spinal Cord. 2000;38(5):309-14. [PMID: 10822404]

68. Hicks AL, Adams MM, Martin Ginis K, Giangregorio L, Latimer A, Phillips SM, McCartney N. Long-term bodyweight supported treadmill training and subsequent followup in persons with chronic SCI: Effects on functional walking ability and measures of subjective well-being. Spinal Cord. 2005;43(5):291-98. [PMID: 15685260]

69. Semerjian TZ, Montague SM, Dominguez JF, Davidian AM, De Leon RD. Enhancement of quality of life and body satisfaction through the use of adapted exercise devices for individuals with spinal cord injuries. Top Spinal Cord Inj Rehabil. 2005;11(2):95-108.

70. Protas EJ, Holmes SA, Qureshy H, Johnson A, Lee D, Sherwood AM. Supported treadmill ambulation training after spinal cord injury: A pilot study. Arch Phys Med Rehabil. 2001;82(6):825-31. [PMID: 11387590]

71. Martin Ginis KA, Latimer AE. The effects of single bouts of body-weight supported treadmill training on the feeling states of people with spinal cord injury. Spinal Cord. 2007; 45(1):112-15. [PMID: 16520818]

72. Martin Ginis KA, Latimer AE, McKechnie K, Ditor DS, McCartney N, Hicks AL, Bugaresti J, Craven B. Using exercise to enhance subjective well-being among people with spinal cord injury: The mediating influences of stress and pain. Rehabil Psychol. 2003;48:157-64.

Submitted for publication February 1, 2007. Accepted in revised form May 31, 2007. 